\title{
DÜBLIN
}

Technological University Dublin

ARROW@TU Dublin

\section{An Integrated Lean Assessment Framework for Tyre Distribution Industry}

Amr Arisha

Technological University Dublin, amr.arisha@tudublin.ie

Amr Mahfouz

Technological University Dublin, amr.mahfouz@tudublin.ie

Follow this and additional works at: https://arrow.tudublin.ie/buschmarcon

Part of the Business Administration, Management, and Operations Commons

\section{Recommended Citation}

Mahfouz, A. \& Arisha, A. (2015). An Integrated Lean Assessment Framework for the Distribution Industry. Proceedings of the 2015 Winter Simulation ConferenceHuntington Beach, California, December 06 - 09.

This Article is brought to you for free and open access by the School of Marketing at ARROW@TU Dublin. It has been accepted for inclusion in Conference papers by an authorized administrator of ARROW@TU Dublin. For more information, please contact arrow.admin@tudublin.ie, aisling.coyne@tudublin.ie,gerard.connolly@tudublin.ie.

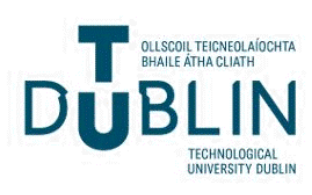


Proceedings of the 2015 Winter Simulation Conference

L. Yilmaz, W. K. V. Chan, I. Moon, T. M. K. Roeder, C. Macal, and M. D. Rossetti, eds.

\title{
AN INTEGRATED LEAN ASSESSMENT FRAMEWORK FOR TYRE DISTRIBUTION INDUSTRY
}

\author{
Amr Mahfouz \\ Amr Arisha \\ 3S Group, College of Business, Dublin Institute of Technology \\ Aungier Street, Dublin 2, IRELAND
}

\begin{abstract}
Given the vital role of distribution units within the supply chains, this research aims to develop a comprehensive lean assessment framework that integrates Modelling and Simulation with Value Stream Mapping (VSM) and Data Envelopment Analysis (DEA) to assess the 'leanness' level in distribution business. The framework is applied on a distribution centre of a leading European company in the tyre manufacturing and distribution business. The framework helps decision makers to evaluate the effect of two lean distribution practices - Pull Order Replenishment and Class-Based Storage Policy - on company's performances and is also used as a leanness Self-Assessment Tool.
\end{abstract}

\section{INTRODUCTION}

The quest to offer high level of service to customers while keeping a worthwhile profit margin under a complex business environment urges DC managers to think of applying the lean management concept to manage and improve their activities. In order to successfully implement lean philosophy, there is a need to track system's improvement through a quantitative leanness index. Hence, this study aims to present a quantitative lean assessment framework to dynamically assess the leanness level of a tyre distribution company. The framework is used as a leanness Self-Assessment tool that enables decision makers to assess company's current state against the ideal leanness state (i.e. no waste or non-value add activities).

\section{STUDIED LEAN PRACTICES}

The company under study supplies tyres for a wide range of customers with an aim to provide an efficient service to fulfil customers demand with an economic cost. Monthly forecasting plans are used however they have low accuracy level in prediction given the system's uncertainty and the high fluctuations of customer demands. Hence, the company faces a challenge with inefficient storing and picking operations due to unplanned storage policy. . As a proposed solution to the problem, two lean practices are suggested, (1) Pull-Replenishment Practice - to reduce the reliance on the forecasting plans and (2) Class-Based Storage Policy which Storing the similar SKUs near together and applying advanced tracking systems.

\section{FRAMEWORK INSIGHTS}

The lean assessment framework encompasses of three components; VSM, Modeling and Simulation, and DEA, (Figure 1). VSM supports the lean assessment efforts by enabling decision makers to visually compare between system's current and future states and clarify sources of waste and non value-added activities. The integration between VSM and simulation facilitates the modeling of system's complexity and provide the ability to concurrently evaluate various performance metrics. The framework has also integrated DEA model with VSM and simulation, see equation 1, in order to calculate a leanness score which enables decision makers to internally assess company's leanness level against the ideal system state. It can also be used to benchmark company's leanness with the companies in the same industry or the lean best practices. 
Mahfouz, Arisha

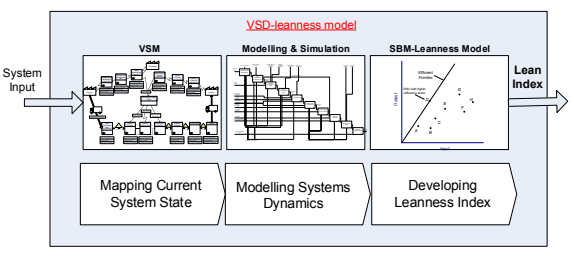

Figure 1: Leanness Assessment Framework

$$
\text { Leanness Score }=\frac{1-\frac{1}{m} \sum_{i=1}^{m} \frac{x_{i A}-x_{i l}}{x_{i A}}}{1+\frac{1}{s} \sum_{r=1}^{s} \frac{y_{s A}-y_{s l}}{y_{S A}}}
$$

where

$x_{i f}$ : Actual input variable $i$

$y_{s, A}$ Actual output variable s

$\mathrm{m}$ and $\mathrm{s}$ : Number of input/output variables

Given that $S_{i}^{-}=x_{i A}-x_{i I}$ $x_{i l}$ : Leanness input variable $i$

$y_{s l}$ L eanness actual output variables

and $S_{r}^{+}=y_{s A}-y_{s I}$

\section{RESULTS}

Lean assessment process starts with identifying the value-added and non value-added activities by mapping the current and future system's states using VSM. Simulation models are then developed for company's current and future states as well as the proposed lean practices. Table 1 illustrates the input and output variables and the results of the simulation models under different system configurations.

Table 1: Simulation Results of the four system states

\begin{tabular}{|c|c|c|c|c|c|c|}
\hline Company & Variable Type & Model Output & \begin{tabular}{|c|} 
Actual \\
DMU \\
\end{tabular} & \begin{tabular}{|c|} 
Pull \\
Replenishment \\
\end{tabular} & \begin{tabular}{|c|} 
Class-based \\
Storage \\
\end{tabular} & $\begin{array}{l}\text { Ideal DMU } \\
\text { (Leanness) }\end{array}$ \\
\hline \multirow{11}{*}{ A } & \multirow{5}{*}{ Input Variables } & Processing Time (days/order) & 2.24 & 2.24 & 1.8 & 1.5 \\
\hline & & Machine Availability (Percentage) & 0.7 & 0.7 & 0.7 & 1 \\
\hline & & Storage Capacity (SKUs) & 300 & 50 & 300 & 50 \\
\hline & & Labour Capacity (Labours) & 13 & 5 & 5 & 5 \\
\hline & & Handling Equipment Capacity (Equipment) & 6 & 2 & 2 & 2 \\
\hline & \multirow{6}{*}{ Output Variables } & Total Order Cycle Time (Days) & 30 & 22 & 17.82 & 2.64 \\
\hline & & Throughput Rate (order/day) & 2.64 & 3 & 2.8 & 3.3 \\
\hline & & Labour Utilisation (Percentage) & 0.5 & 0.55 & 0.55 & 0.7 \\
\hline & & Equipment Utilisation (Percentage) & 0.5 & 0.6 & 0.5 & 0.7 \\
\hline & & Number of Lateness Orders (Orders) & 301 & 240 & 101 & 1 \\
\hline & & Inventory Level (SKUs) & 13304 & 7500 & 10000 & 5500 \\
\hline
\end{tabular}

Finally DEA model (i.e. Slack Based Measurement Model (SBM)) calculates the leanness score, Figure 2, based on the simulation results using the following equations:

Leanness Score (System's Current State)

$$
\begin{aligned}
& =\frac{1-\frac{1}{5}\left(\frac{2.24-1.5}{2.24}+\frac{0.7-1}{0.7}+\frac{300-50}{300}+\frac{13-5}{13}+\frac{6-2}{6}\right)}{1+\frac{1}{6}\left(\frac{30-2.64}{30}+\frac{2.64-3.3}{2.64}+\frac{0.5-0.7}{0.5}+\frac{0.5-0.7}{0.5}+\frac{301-1}{301}+\frac{13304-5500}{13304}\right)} \\
& =0.35
\end{aligned}
$$

Leanness Score (System under Pull - Replenishment Practice)

$$
\begin{gathered}
=\frac{1-\frac{1}{5}\left(\frac{2.24-1.5}{2.24}+\frac{0.7-1}{0.7}+\frac{50-50}{50}+\frac{5-5}{5}+\frac{2-2}{2}\right)}{1+\frac{1}{6}\left(\frac{22-2.64}{22}+\frac{3-3.3}{3}+\frac{0.55-0.7}{0.55}+\frac{0.6-0.7}{0.6}+\frac{240-1}{240}+\frac{7500-5500}{7500}\right)}=0.56 \\
\text { Leanness Score (System under Class - Based Storage Policy) } \\
=\frac{1-\frac{1}{5}\left(\frac{1.8-1.5}{1.8}+\frac{0.7-1}{0.7}+\frac{300-50}{300}+\frac{5-5}{5}+\frac{2-2}{2}\right)}{1+\frac{1}{6}\left(\frac{17.82-2.64}{17.82}+\frac{2.8-3.3}{2.8}+\frac{0.55-0.7}{0.55}+\frac{0.5-0.7}{0.5}+\frac{101-1}{101}+\frac{10000-5500}{10000}\right)}
\end{gathered}
$$

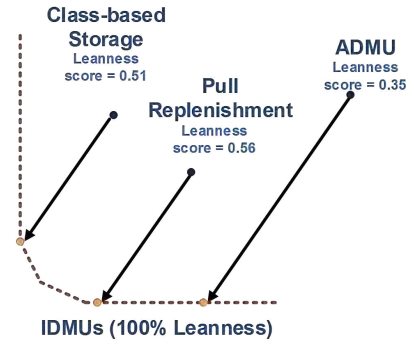

Figure 2: Leanness levels

\section{CONCLUSION}

- It is envisaged to be useful to develop a framework that can dynamically evaluate the leanness level of the distribution operations within the tyre distribution business.

- The framework is a leanness Self-Assessment tool that enables decision makers to measure company's current leanness status against the ideal status (i.e. no waste or non-value added activities).

- The use of the framework provides a safer, cost effective, and less disruptive tool to implement and assess the lean implementation compared to the trial-and-error approach. 